\title{
Readmission Rates for Chronic Obstructive Pulmonary Disease Under the Hospital Readmissions Reduction Program: an Interrupted Time Series Analysis
}

\author{
Russell G. Buhr, MD, $P h D^{7,2,3,4} \mathbb{D}_{0}$, Nicholas J. Jackson, $P h D, M P H^{5}$, \\ Gerald F. Kominski, $P h D^{2,6}$, Steven M. Dubinett, $\mathrm{MD}^{1,3}$, Carol M. Mangione, MD, MSPH ${ }^{2,7}$, \\ and Michael K. Ong, MD, $P h D^{2,3,4,7}$
}

\begin{abstract}
'Division of Pulmonary and Critical Care Medicine, David Geffen School of Medicine, University of California, Los Angeles Los Angeles, CA, USA; ${ }^{2}$ Department of Health Policy and Management, Jonathan and Karin Fielding School of Public Health, University of California, Los Angeles Los Angeles, CA, USA; ${ }^{3}$ Department of Medicine, Greater Los Angeles Veterans Affairs Healthcare SystemLos Angeles, CA, USA; ${ }^{4}$ Center for the Study of Healthcare Innovation, Implementation, and Policy, Health Services Research \& Development, Greater Los Angeles Veterans Affairs Healthcare SystemLos Angeles, CA, USA; ${ }^{5}$ Department of Medicine Statistics Core, University of California, Los AngelesLos Angeles, CA, USA; ${ }^{6} \mathrm{C}$ enter for Health Policy Research, Jonathan and Karin Fielding School of Public Health, University of California, Los AngelesLos Angeles, CA, USA; ${ }^{7}$ Division of General Internal Medicine and Health Services Research, David Geffen School of Medicine, University of California, Los AngelesLos Angeles, CA, USA.
\end{abstract}

BACKGROUND: Hospital readmission rates decreased for myocardial infarction (AMI), heart failure (CHF), and pneumonia with implementation of the first phase of the Hospital Readmissions Reduction Program (HRRP). It is not established whether readmissions fell for chronic obstructive pulmonary disease (COPD), an HRRP condition added in 2014.

OBJECTIVE: We sought to determine whether HRRP penalties influenced COPD readmissions among Medicare, Medicaid, or privately insured patients.

DESIGN: We analyzed a retrospective cohort, evaluating readmissions across implementation periods for HRRP penalties ("pre-HRRP" January 2010-April 2011, "implementation" May 2011-September 2012, "partial penalty" October 2012-September 2014, and "full penalty" October 2014-December 2016).

PATIENTS: We assessed discharged patients $\geq 40$ years old with COPD versus those with HRRP Phase 1 conditions (AMI, CHF, and pneumonia) or non-HRRP residual diagnoses in the Nationwide Readmissions Database.

INTERVENTIONS: HRRP was announced and implemented during this period, forming a natural experiment. MEASUREMENTS: We calculated differences-indifferences (DID) for 30-day COPD versus HRRP Phase 1 and non-HRRP readmissions.

KEY RESULTS: COPD discharges for 1.2 million Medicare enrollees were compared with 22 million non-HRRP and 3.4 million HRRP Phase 1 discharges. COPD readmissions decreased from 19 to $17 \%$ over the study. This reduction was significantly greater than non-HRRP conditions (DID - 0.41\%), but not HRRP Phase 1 (DID + $0.02 \%$ ). A parallel trend was observed in the privately

Carol M. Mangione and Michael K. Ong are co-senior authors.

Prior Presentation None

Electronic supplementary material The online version of this article (https://doi.org/10.1007/s11606-020-05958-0) contains supplementary material which is available to authorized users.

Received March 9, 2020

Accepted June 4, 2020

Published online June 17, 2020 insured, with significant reduction compared with nonHRRP (DID - 0.83\%), but not HRRP Phase 1 conditions (DID - 0.45\%). Non-significant reductions occurred in Medicaid (DID $-0.52 \%$ vs. non-HRRP and $-0.21 \%$ vs. Phase 1 conditions).

CONCLUSIONS: In Medicare, HRRP implementation was associated with reductions in COPD readmissions compared with non-HRRP controls but not versus other HRRP conditions. Parallel findings were observed in commercial insurance, but not in Medicaid. Condition-specific penalties may not reduce readmissions further than existing HRRP trends.

KEY WORDS: COPD; comorbidity; readmission; multilevel modeling.

$\mathrm{J}$ Gen Intern Med 35(12):3581-90

DOI: $10.1007 / \mathrm{s} 11606-020-05958-0$

(c) Society of General Internal Medicine 2020

\section{INTRODUCTION}

Rehospitalizations are frequent and costly, particularly among Medicare beneficiaries, where nearly $20 \%$ return within a month of discharge. ${ }^{1}$ In efforts to curtail costs and promote quality, the Affordable Care Act (ACA) set groundwork for the Hospital Readmissions Reduction Program (HRRP), reducing Medicare reimbursements to hospitals with excess 30day readmissions for certain conditions. ${ }^{2}$ The Centers for Medicare and Medicaid Services (CMS) enacted penalties for acute myocardial infarction (AMI), pneumonia (PNA), and congestive heart failure (CHF) in October 2012, ${ }^{3,4}$ followed by chronic obstructive pulmonary disease (COPD) in October 2014. ${ }^{5,6}$ Within COPD alone, readmission expenditures exceed $\$ 15$ billion annually, ${ }^{7}$ making readmission reductions attractive for reducing costs.

In the first phase of HRRP penalties (for CHF, AMI, and pneumonia, hereafter referred to as "HRRP Phase 1"), readmission rated diminished in Medicare, ${ }^{8}$ even more robustly in 


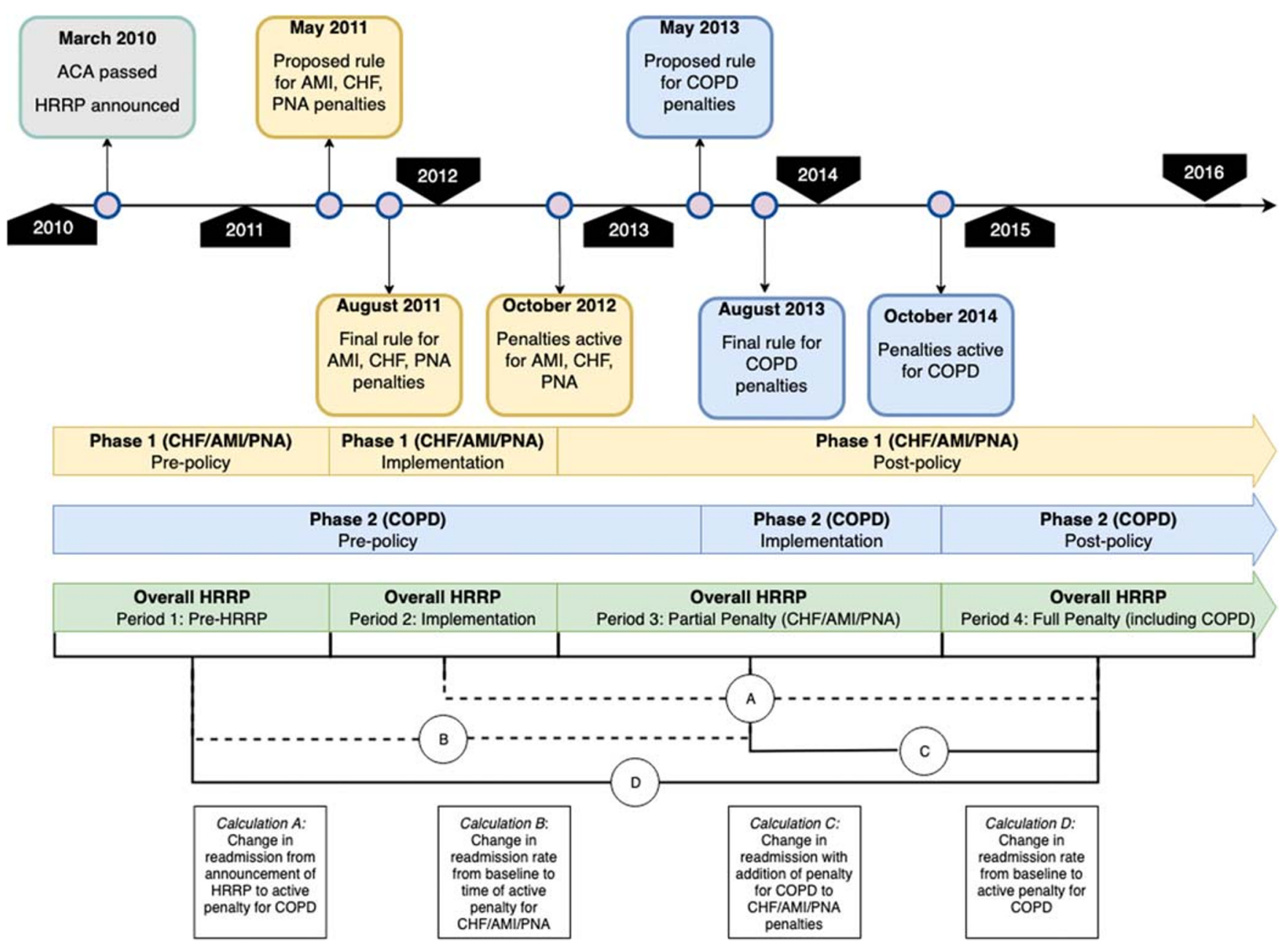

Figure 1 Timeline for HRRP implementation and penalty periods with summary of calculations for interrupted time series analyses. Yellow bars delineate timeline for implementation and active penalties for CHF/AMI/PNA while blue bars delineate those for COPD. Green bars represent the aggregate time periods used for these analyses. Main calculations are lettered below where each calculation lettered corresponds to the periods in the boxes below the timeline.

hospitals participating in value-based payments. ${ }^{9}$ In all-payer samples preceding the addition of COPD to HRRP, readmission reductions occurred for both HRRP targets and nonpenalized conditions. ${ }^{10,11}$ COPD readmissions began to decrease even before HRRP penalties were implemented, ${ }^{12,} 13$ but there are limited data on HRRP's effect on COPD after penalty activation. Condition-specific readmission measures penalize fewer hospitals,${ }^{14}$ though the incremental effect of adding individual conditions to HRRP is unknown. Additionally, while HRRP imposes penalties only within Medicare, evidence of HRRP effects on readmissions spilling over into non-Medicare populations is inconsistent. ${ }^{11,15,16}$

We sought to answer two key questions using a nationally representative, all-payer sample of discharges that spans all phases of HRRP. First, we investigate whether COPD readmission rates within Medicare decreased with the addition of COPD-specific penalties to the HRRP by a greater magnitude than pre-existing trends. Second, we evaluate whether there were significant reductions in COPD readmission rates among Medicaid and privately insured populations. This approach fills a gap by evaluating the effect and incremental utility of adding COPD to the HRRP and by assessing HRRP's effects on COPD readmissions in non-Medicare populations.

\section{METHODS}

\section{Data Source and Inclusion Criteria}

We collated discharges from the Nationwide Readmissions Database (NRD) from January 2010 to December 2016. Data analyzed in this study are available from the Agency for Healthcare Research and Quality (AHRQ). ${ }^{17}$ This database is an all-payer, $100 \%$ sample of acute care discharges across multiple states and, with sampling weights, approximates > $50 \%$ of the national population. ${ }^{7}$ We defined index hospitalizations by HRRP methodology: $\geq 30$ days since prior hospitalization, discharged alive, and not against medical advice. ${ }^{18}$, ${ }^{19}$ While HRRP applies to Medicare beneficiaries $\geq 65$ years old, we used a liberal age cutoff of $\geq 40$ years as to include more Medicaid and privately insured. For each condition (AMI, CHF, PNA, COPD), we created an indicator based on the HRRP ICD-9 and ICD-10 inclusion codes. ${ }^{18,}{ }^{19} \mathrm{We}$ 
a

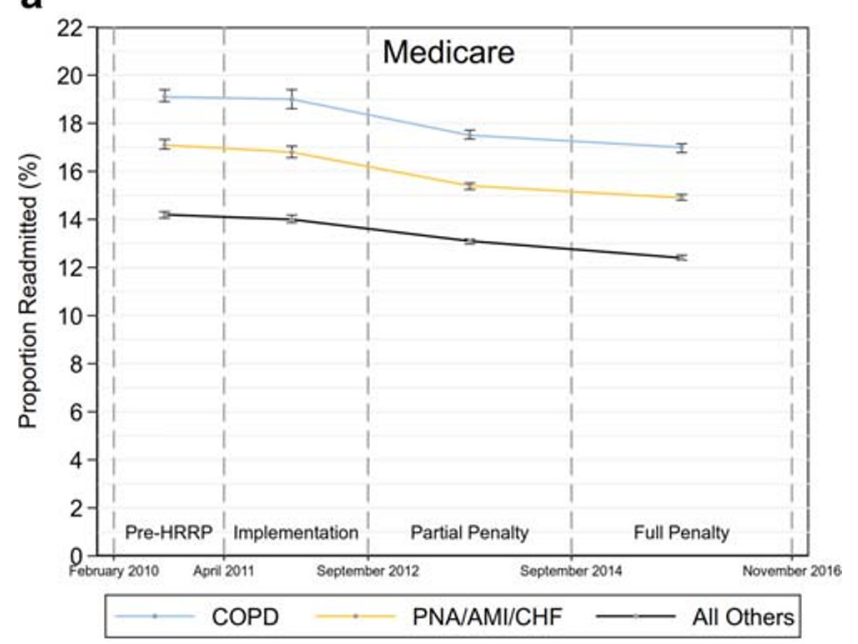

b

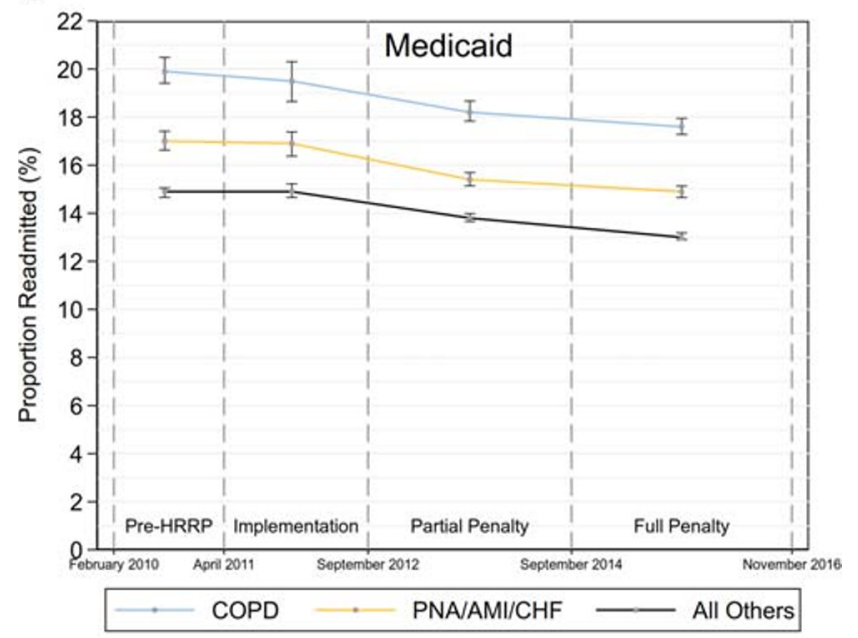

C

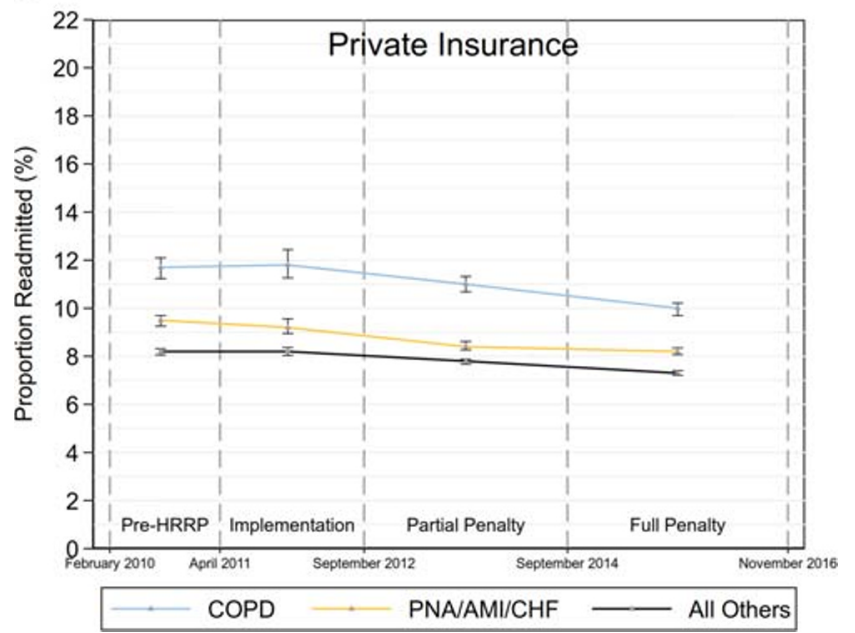

Figure 2 Risk-adjusted estimates of mean readmission rates and 95\% CI for COPD (blue), HRRP Phase 1 conditions of congestive heart failure, pneumonia, and acute myocardial infarction (yellow), and non-HRRP conditions (black) over HRRP periods by payer type: (a) Medicare, (b) Medicaid, (c) Private insurance. grouped diagnoses by phase they entered HRRP: AMI, CHF, and PNA designated as "Phase 1," COPD "Phase 2," and the residual "non-HRRP."

\section{Measurements and Covariates}

We defined readmission as return to any acute care hospital for any cause within 30 days of discharge from index hospitalization, omitting certain diagnoses or procedures exempted in HRRP (e.g., organ transplantation, elective surgeries, childbirth, or chemotherapy). ${ }^{18,19}$ We derived the Elixhauser Comorbidity Index from ICD codes, adapting a published algorithm ${ }^{20}$ for the AHRQ 2017 updated model. ${ }^{21}$ Patient and hospital variables (e.g., sociodemographics, payer, hospital characteristics) were provided in the dataset and managed Medicare and dual-eligible patients were classified as Medicare, while managed Medicaid was classified as Medicaid. ${ }^{7}$

\section{Interrupted Time Series Analyses}

Time periods for interrupted time series (ITS) analyses were developed from dates published in the Federal Register. ${ }^{3-6}$ Because periods for COPD and HRRP Phase 1 conditions (CHF/AMI/PNA) were asynchronous, we aggregated our timeline into four periods to align comparisons between the two phases (Fig. 1). Thus, for our analyses, we defined "preHRRP" as prior to the first proposed rule defining any HRRP conditions and "implementation" as time between this proposed rule and penalty activation for CHF, pneumonia, and AMI. We defined time penalties were only active for Phase 1 as "partial penalty" and time penalties were also active for COPD as "full penalty" (Fig. 1). Using these bounds, piecewise regression models were fit to estimate mean readmission rates by HRRP period, with separate models by insurance type. Within each model, we included fixed effects for policy period, quarter of year (to adjust for observed within-year variations), and readmission-weighted Elixhauser Comorbidity Index score. ${ }^{21}$ The Elixhauser Index was chosen for risk adjustment as it correlates well with COPD readmission risk, ${ }^{22}$ and due to inability to classify risk as modeled in $\mathrm{HRRP}^{18,19}$ owing to data limitations. Models used Huber-White robust standard errors for hospital-level clustering.

We employed difference-in-differences analyses to determine the change in readmission rates across the policy periods between the COPD cohort and the aggregated cohort of HRRP Phase 1 conditions (CHF, pneumonia, and AMI) in order to evaluate the incremental effect of adding COPD-specific penalties. We compared COPD with non-HRRP diagnoses to establish background secular trends in readmission rates with time, independent of policy effects. A threshold of $10 \%$ missingness for modeled variables was chosen a priori to trigger multiple imputation, which was not reached. Complete case analysis was used in all models, with survey weights provided with the database ${ }^{7}$ applied for national representativeness. Analyses were performed in Stata 15.1 (StataCorp, College Station, TX). 
Table 1 COPD Patient-Level Characteristics by HRRP Period by Payer

\begin{tabular}{|c|c|c|c|c|c|c|c|c|c|c|c|c|}
\hline & \multicolumn{4}{|c|}{ Medicare $(N=1,165,378)$} & \multicolumn{4}{|c|}{ Medicaid $(N=205,935)$} & \multicolumn{4}{|c|}{ Private insurance $(N=187,959)$} \\
\hline & $\begin{array}{l}\text { Period } \\
1^{\dagger}\end{array}$ & $\begin{array}{l}\text { Period } \\
2\end{array}$ & $\begin{array}{l}\text { Period } \\
3\end{array}$ & $\begin{array}{l}\text { Period } \\
4\end{array}$ & $\begin{array}{l}\text { Period } \\
1\end{array}$ & $\begin{array}{l}\text { Period } \\
2\end{array}$ & $\begin{array}{l}\text { Period } \\
3\end{array}$ & $\begin{array}{l}\text { Period } \\
4\end{array}$ & $\begin{array}{l}\text { Period } \\
1\end{array}$ & $\begin{array}{l}\text { Period } \\
2\end{array}$ & $\begin{array}{l}\text { Period } \\
3\end{array}$ & $\begin{array}{l}\text { Period } \\
4\end{array}$ \\
\hline \multicolumn{13}{|l|}{ Sex, $\%$} \\
\hline Female & $59 \%$ & $59 \%$ & $59 \%$ & $59 \%$ & $64 \%$ & $64 \%$ & $63 \%$ & $62 \%$ & $58 \%$ & $59 \%$ & $58 \%$ & $58 \%$ \\
\hline $\begin{array}{l}\text { Age, mean } \pm \\
\text { SD }\end{array}$ & $72 \pm 10$ & $72 \pm 10$ & $72 \pm 10$ & $72 \pm 11$ & $56 \pm 8$ & $56 \pm 8$ & $56 \pm 8$ & $56 \pm 8$ & $61 \pm 9$ & $61 \pm 9$ & $61 \pm 9$ & $61 \pm 10$ \\
\hline \multicolumn{13}{|c|}{ Median household income, \% } \\
\hline 1st quartile & $36 \%$ & $37 \%$ & $34 \%$ & $35 \%$ & $49 \%$ & $50 \%$ & $47 \%$ & $49 \%$ & $31 \%$ & $31 \%$ & $29 \%$ & $31 \%$ \\
\hline 2nd quartile & $26 \%$ & $25 \%$ & $28 \%$ & $27 \%$ & $25 \%$ & $24 \%$ & $26 \%$ & $25 \%$ & $27 \%$ & $26 \%$ & $28 \%$ & $27 \%$ \\
\hline 3 rd quartile & $21 \%$ & $21 \%$ & $21 \%$ & $22 \%$ & $17 \%$ & $17 \%$ & $16 \%$ & $17.2 \%$ & $24 \%$ & $24 \%$ & $24 \%$ & $25 \%$ \\
\hline 4th quartile & $15 \%$ & $15 \%$ & $15 \%$ & $14 \%$ & $8 \%$ & $8 \%$ & $8 \%$ & $8 \%$ & $17 \%$ & $18 \%$ & $18 \%$ & $16 \%$ \\
\hline Missing & $2 \%$ & $1 \%$ & $1 \%$ & $1 \%$ & $2 \%$ & $2 \%$ & $2 \%$ & $1 \%$ & $2 \%$ & $2 \%$ & $2 \%$ & $1 \%$ \\
\hline Number of & $2.6 \pm$ & $2.6 \pm$ & $2.5 \pm$ & $2.5 \pm$ & $2.9 \pm$ & $3.0 \pm$ & $2.9 \pm$ & $2.9 \pm$ & $2.1 \pm$ & $2.1 \pm$ & $2.1 \pm$ & $2.0 \pm$ \\
\hline $\begin{array}{l}\text { admissions } \\
\text { each patient } \\
\text { had over a } \\
\text { year, mean } \pm \\
\text { SD }\end{array}$ & 1.9 & 1.9 & 1.9 & 2.0 & 2.3 & 2.4 & 2.4 & 2.6 & 1.6 & 1.6 & 1.6 & 1.8 \\
\hline Number & $1.2 \pm$ & $1.2 \pm$ & $1.1 \pm$ & $1.2 \pm$ & $1.3 \pm$ & $1.3 \pm$ & $1.2 \pm$ & $1.3 \pm$ & $1.2 \pm$ & $1.2 \pm$ & $1.1 \pm$ & $1.2 \pm$ \\
\hline $\begin{array}{l}\text { hospitals } \\
\text { where each } \\
\text { patient } \\
\text { received care } \\
\text { over a year, } \\
\text { mean } \pm \mathrm{SD}\end{array}$ & 0.5 & 0.5 & 0.4 & 0.5 & 0.6 & 0.6 & 0.5 & 0.7 & 0.4 & 0.4 & 0.3 & 0.5 \\
\hline \multicolumn{13}{|c|}{ Discharge disposition, $\%$} \\
\hline $\begin{array}{l}\text { Routine to } \\
\text { home }\end{array}$ & $62 \%$ & $62 \%$ & $60 \%$ & $60 \%$ & $83 \%$ & $82 \%$ & $81 \%$ & $80 \%$ & $84 \%$ & $83 \%$ & $83 \%$ & $82 \%$ \\
\hline $\begin{array}{l}\text { Transfer to } \\
\text { post-acute }\end{array}$ & $16 \%$ & $16 \%$ & $16 \%$ & $16 \%$ & $7 \%$ & $7 \%$ & $6 \%$ & $6 \%$ & $5 \%$ & $5 \%$ & $5 \%$ & $5 \%$ \\
\hline care & & & & & & & & & & & & \\
\hline $\begin{array}{l}\text { Home with } \\
\text { home health }\end{array}$ & $21 \%$ & $21 \%$ & $22 \%$ & $23 \%$ & $10 \%$ & $11 \%$ & $12 \%$ & $13 \%$ & $10 \%$ & $11 \%$ & $12 \%$ & $12 \%$ \\
\hline $\begin{array}{l}\text { services } \\
\text { Other }\end{array}$ & $1 \%$ & $1 \%$ & $1 \%$ & $1 \%$ & $1 \%$ & $1 \%$ & $1 \%$ & $<1 \%$ & $1 \%$ & $1 \%$ & $1 \%$ & $1 \%$ \\
\hline Length of & $4.0 \pm$ & $3.9 \pm$ & $3.8 \pm$ & $3.8 \pm$ & $3.7 \pm$ & $3.6 \pm$ & $3.6 \pm$ & $3.5 \pm$ & $3.6 \pm$ & $3.5 \pm$ & $3.5 \pm$ & $3.4 \pm$ \\
\hline $\begin{array}{l}\text { atay }^{\$} \text {, mean } \\
\pm \mathrm{SD}\end{array}$ & 2.1 & 2.0 & 2.0 & 2.2 & 2.1 & 1.9 & 2.0 & 2.1 & 1.9 & 1.8 & 1.9 & 2.0 \\
\hline
\end{tabular}

Unweighted N's displayed. Frequencies derived using weighted analysis

Within each insurance type, $P$ value for trend was $<0.001$ for all variables

${ }^{S}$ Geometric mean and $S D$ for log transformed variable presented

†Period 1 (pre-HRRP) defined as February 2010-April 2011, period 2 (implementation) May 2011-September 2012, period 3 (partial penalty) October 2012-September 2014, and period 4 (full penalty) October 2014-November 2016

Details about data specification and modeling are found in the supplementary appendix. This study was exempted from review based on its use of deidentified, publicly available data by the UCLA Institutional Review Board (IRB No. 18001208).

\section{RESULTS}

\section{Characteristics of the Study Sample}

Among Medicare patients, an unweighted sample of $1,165,378$ COPD hospitalizations occurred during the study period with an overall unadjusted readmission rate of $18.2 \%$ (Appendix Table 1). We referenced these stays against an aggregate of AMI $(N=582,329$, overall readmission rate $15.0 \%)$, CHF $(N=1,284,024$, overall readmission rate $20.0 \%)$, pneumonia $(N=1,487,237$, overall readmission rate $15.5 \%)$, and the non-HRRP residual hospitalizations $(N=$ $22,044,760$, overall readmission rate $13.0 \%$ ). Observed lengths of stay for COPD decreased over policy periods, with more patients in Medicare and fewer in Medicaid and private insurance using home care services (Table 1). Parallel patterns were observed for HRRP Phase 1 (Appendix Table 2) and non-HRRP conditions (Appendix Table 2). Teaching and nonprofit hospitals were more frequently observed in the sample and hospitals became proportionally smaller over the 7 years of observation (Table 2). The crude mean proportion of patient-days paid by Medicaid within hospitals also increased, from 16 to $18 \%$ by the full penalty period (Table 2). States included in each year's sample were not uniform throughout the study, which may explain some variation. ${ }^{7}$

\section{Readmission Trends}

Raw readmission rates for each condition and insurance type decreased over the duration of the study period (Appendix Figures 1-3). COPD readmissions from pre-HRRP to full penalty period decreased from 18.9 to $17.7 \%$ in Medicare, from 19.5 to $18.2 \%$ in Medicaid, and from 12.6 to $11.7 \%$ in private insurance (Appendix Table 1). In risk-adjusted interrupted time series models, we calculated estimates of 
Table 2 All-Payer Hospital Characteristics for COPD Hospitalizations by HRRP Period

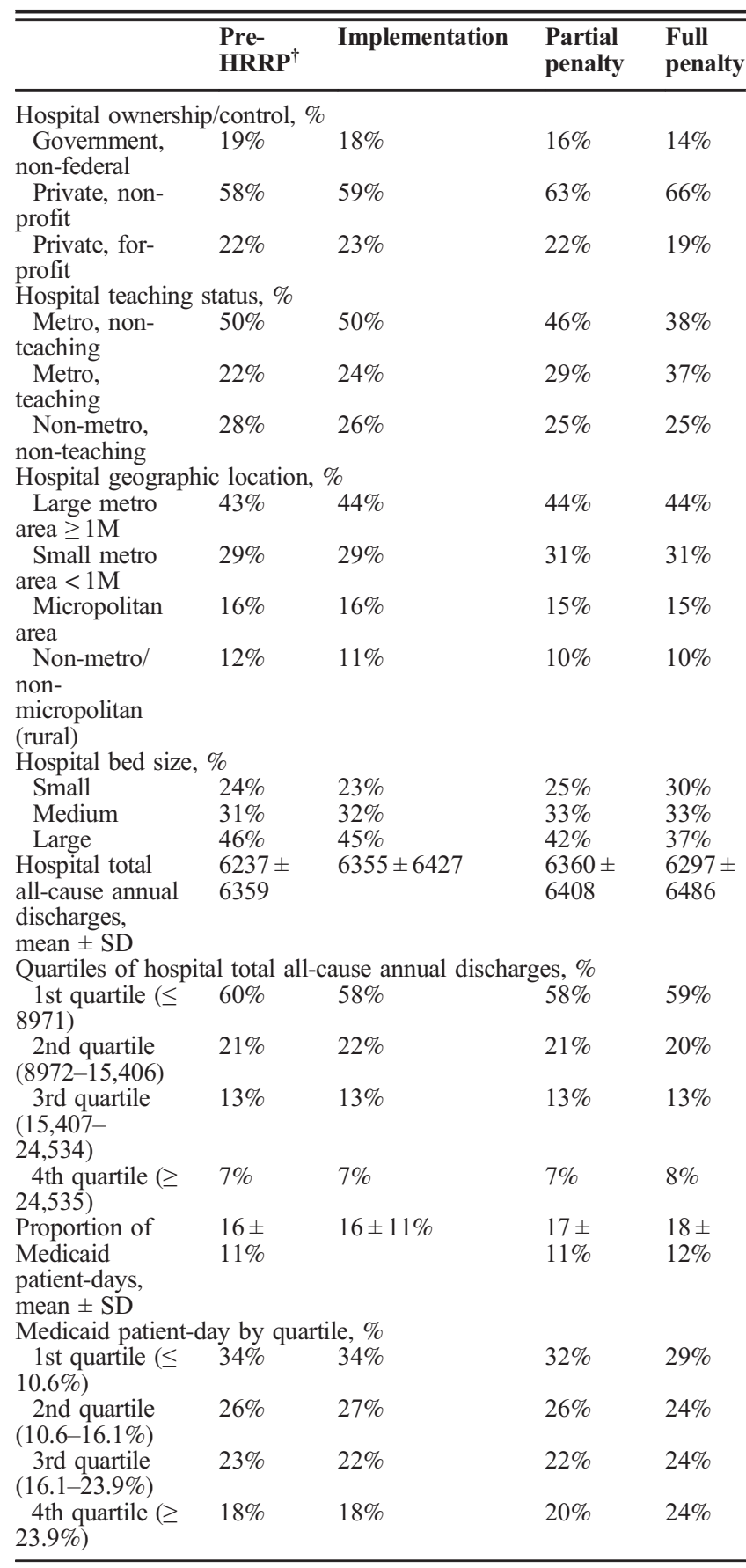

Unweighted frequencies displayed for cohort proportions. $P$ value for trend was $<0.001$ for all variables. Quartile bins based on entire database (all conditions) distribution

†Period 1 (Pre-HRRP) defined as February 2010-April 2011, period 2 (implementation) May 2011-September 2012, period 3 (partial penalty) October 2012-September 2014, and period 4 (full penalty) October 2014-November 2016

mean readmission rates within each study period for COPD, HRRP Phase 1, and non-HRRP conditions by payer (Fig. 2). In Medicare, risk-adjusted COPD readmissions decreased from $19.1 \%$ during pre-HRRP period to $17.5 \%$ in partial penalty period (when Phase 1 HRRP penalties were enacted), further decreasing to $17.0 \%$ within full penalty period (inclusive of COPD penalties) (Appendix Table 4). During these same time periods, HRRP Phase 1 readmissions decreased from 17.1 to $15.4 \%$ in partial penalty period and $14.9 \%$ in full penalty period. Among non-HRRP conditions, rates decreased from 14.2 to $13.1 \%$ in partial penalty and to $12.4 \%$ in full penalty period.

\section{Difference-in-Differences Among Medicare Beneficiaries}

In difference-in-differences (DID) analyses, adjusted COPD readmission rates fell significantly more than the secular trend among non-HRRP conditions between the pre-HRRP to full penalty periods (DID $-0.41 \%, P=0.005$ ). Examining additional change in readmissions transitioning from partial to full penalty periods, no significant difference was observed (DID $+0.10 \%, P=0.413)$. In contrast, COPD readmission rates were not significantly different than those for aggregated Phase 1 conditions from pre-HRRP to full penalty (DID + $0.02 \%, P=0.880$; Table 3 ), nor was there a significant difference transitioning from the partial to full penalty period (DID $-0.10 \%, P=0.406)$.

\section{Effects on Non-Medicare Patients}

In Medicaid, mean risk-adjusted COPD readmission rates were $19.9 \%$ during pre-HRRP, falling to $18.2 \%$ in partial penalty and $17.6 \%$ during full penalty periods (Table 3 ). Comparing this reduction of $2.33 \%$ in COPD, non-HRRP rates dropped by $1.81 \%$ over the same time, a non-significant difference-indifferences of $-0.52 \%(P=0.103$; Table 3$)$. Similarly, there also was no significant difference in readmission rate reduction for COPD compared with Phase 1 conditions across these periods (DID $-0.21 \%, P=0.602$; Table 3 ).

Among privately insured, COPD readmissions fell from 11.7 to $10.0 \%$ from pre-HRRP to full penalty phase, a greater degree than non-HRRP conditions over this time (DID -0.83 , $P=0.001$; Table 3). Conversely, when comparing COPD readmissions with aggregate HRRP Phase 1 conditions, no significant differences were observed in rate reduction (DID $0.45 \%, P=0.100$; Table 3). Looking at the transition from partial to full penalty periods, however, an additional reduction of $-0.81 \%$ in COPD rates was observed when compared with Phase 1 diagnoses $(P<0.001)$.

\section{Sensitivity Analyses}

Because we were unable to model the exact risk adjustment method used by CMS, we also fit models without the Elixhauser Comorbidity Index to obtain non-risk-adjusted estimates. In this approach, COPD readmission rates in Medicare did not change significantly differently than non-HRRP conditions (DID $-0.15 \%, P=0.291$; Appendix Tables 5-6), and fell significantly less than HRRP Phase 1 diagnoses (DID $+0.45 \%, P=0.005$ ). Similarly, no significant differences were 


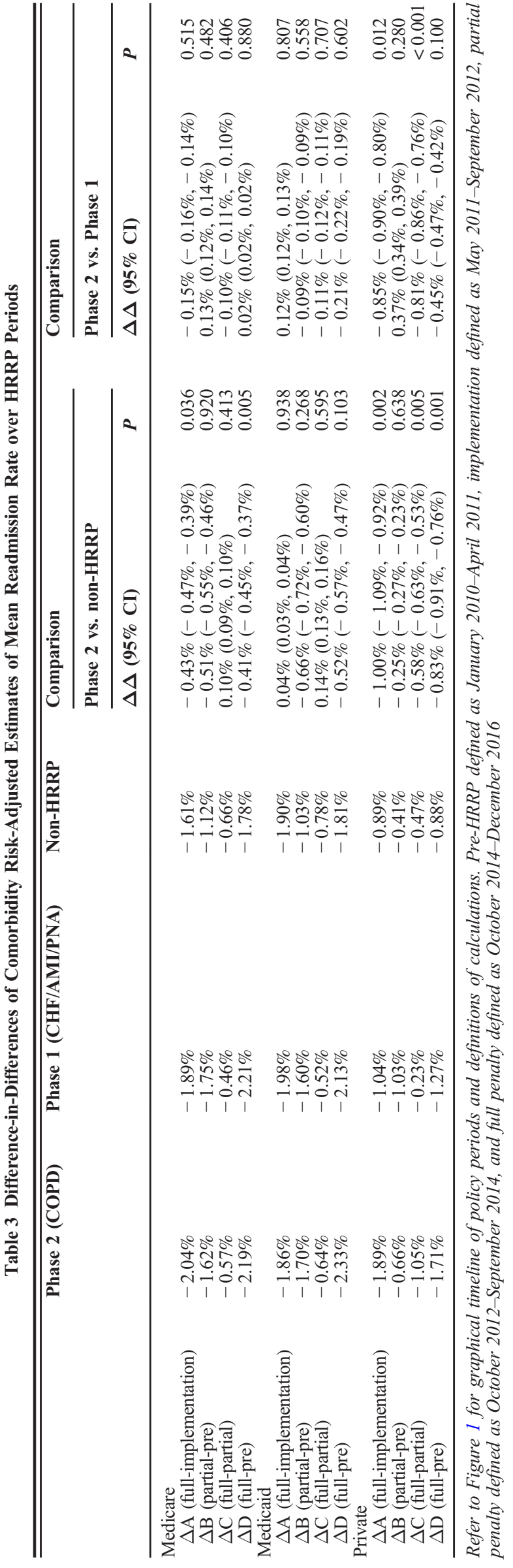

observed in Medicaid compared with either HRRP Phase 1 (DID $+0.64 \%, P=0.108$ ) or non-HRRP conditions (DID $0.07 \%, P=0.837$; Appendix Tables 5-6). Among the privately insured, no significant difference in change was observed compared with Phase 1 (DID $+0.32 \%, P=0.275$ ), or nonHRRP conditions (DID $-0.54 \%, P=0.059$; Appendix Tables 5-6.

We evaluated the effect of restricting the Medicare cohort to patients aged $\geq 65$ years. In this restricted model, adjusted for Elixhauser Index and discharge quarter, we found a significant difference between COPD rates from pre-HRRP to full penalty compared with non-HRRP conditions (DID $-0.50 \%, P=$ 0.001; Appendix Table 8), which was greater than that for the unrestricted Medicare cohort (DID $-0.41 \%, P=0.005$; Table 3). This was not observed compared with Phase 1 HRRP conditions (DID + 0.04\%, $P=0.809$; Appendix Tables 7-8).

\section{DISCUSSION}

Our study evaluated changes in readmission rates for COPD across periods of HRRP's inception, implementation, and penalty phases using a quasi-experimental approach. By comparing with non-HRRP conditions, we evaluated whether COPD readmissions changed more than background trends, finding that among Medicare beneficiaries, COPD readmissions rates fell more than rates for conditions not penalized under HRRP. The magnitude of change was slightly greater in our sensitivity analysis of Medicare patients $\geq$ 65 years old, with a 2.3 percentage point reduction in COPD readmissions over the study period (Appendix Table 8). In addition to this statistically significant change, a reduction in readmission rates by this magnitude would have substantial clinical and economic impact, reducing the number of occupied beds and decreasing expenditures.

We also investigated whether the addition of COPD to HRRP penalties was associated with greater rate reduction than that observed in absence of COPD-specific sanctions, including the other HRRP conditions as a second comparator. In contrast to the first comparison, no difference in readmission rate change over policy periods was observed when compared the diagnoses of heart failure, myocardial infarction, and pneumonia in the Medicare cohort. Additionally, the majority of the reduction in COPD readmissions which had occurred before penalties became active in October 2014 (1.62\% reduction before COPD penalties and an additional $0.57 \%$ reduction after their addition; Appendix Table 3), though no significant difference in change was noted in the partial to full penalty period transition.

Taken together, these findings highlight that while HRRP is associated with decreased readmission rates for COPD compared with secular trends in non-penalized conditions, adding COPD-specific penalties did not correlate with reductions greater than what was occurring already in the other HRRP diagnoses. This raises the question of whether adding COPD 
penalties was necessary to reduce readmission rates. It is possible that threat of further penalties sufficiently influenced health system practices to the point that there was no marginal benefit on COPD readmission rates with the additional penalty. Hospital leaders reported in a national survey that HRRP influenced decisions to implement readmission reduction programs. ${ }^{23}$ In the case of COPD, it may suggest that the overall effects of HRRP on health system and hospital practices affected readmission rates even without condition-specific penalization.

While HRRP is specific to Medicare, many changes to health system practices would have been applied to entire patient populations regardless of payer. While COPD readmissions decreased among Medicaid beneficiaries, these trends were not significantly different than controls, suggesting that these reductions were not specifically associated with HRRP in this population. We observed a potential spillover effect among privately insured patients, where significant relative reductions in COPD rates occurred compared with the non-HRRP conditions. Disparate outcomes in Medicaid are highlighted in other studies of HRRP and may be related to differential resources and programs available compared with Medicare or commercial insurance. ${ }^{24-26}$

Readmission reduction programs would have been underway in hospitals seeking to reduce their risk for penalties in other HRRP conditions prior to the addition of the COPD penalty. Many interventions used would not have been condition-specific, such as transitional care programs, disease selfmanagement plans, and other strategies targeted at adherence to treatment. ${ }^{27-29}$ Health systems may have recognized the prevalence of COPD readmissions and anticipated that COPD would be a logical extension of the policy. COPD-specific programs may have been deployed in advance of HRRP's finalization, evidenced by studies on COPD programs published prior to the penalty. ${ }^{27,30}$

Though a high proportion of readmissions may be preventable, ${ }^{31}$ HRRP does not take measures of potential avoidability into account when assigning penalties. Risk stratification tools for discerning avoidable readmissions are validated at the hospital level, ${ }^{32-34}$ though their use of clinical variables limits their adoption for policy purposes. Additionally, while HRRP penalizes all-cause readmissions, addressing whether return visits were attributable to the same principal diagnosis may give more information about quality of care. In COPD, less than half of rehospitalizations are attributable to recurrent COPD under HRRP definitions. ${ }^{35}$ The effect of multimorbidity on COPD readmissions is particularly confounding. ${ }^{36}$

While not analyzed in our study, the unintended consequence of the HRRP is a subject of continued debate. Mortality increase as a tradeoff for reductions in readmission remains a concern, though evidence as to whether mortality rates in CHF, AMI, and pneumonia increased with HRRP is not unanimous. ${ }^{37,}{ }^{38} \mathrm{In}$ an analysis of CMS hospital-level data on COPD, as readmissions fell, all-cause risk-standardized mortality increased, ${ }^{39}$ though COPD-specific mortality has not been evaluated. The potential disproportionate penalization of safety net hospitals is another concern, ${ }^{40-43}$ particularly in COPD ${ }^{44}$ The effects of the HRRP expansion to include COPD on these outcomes require further study.

There are concerns about the validity of readmission rates as a good measure of accountability for care quality in COPD. ${ }^{45}$ Despite this, COPD readmission rates correlate with other markers of hospital quality and patient satisfaction, supporting HRRP as a lever to improve quality. ${ }^{46}$ The simple reduction of readmission rates is likely an insufficient marker of COPD care quality, and future alternative payment models should account for additional indicators, such as participation pulmonary rehabilitation, ${ }^{47,}{ }^{48}$ smoking cessation counseling, ${ }^{49}, 50$ adequate vaccination rates, ${ }^{51,52}$ and guideline adherence in diagnostic and treatment regimens. ${ }^{53}$

\section{Limitations}

Data available for our analyses were limited to 2010 through 2016 and do not identify which specific hospitals were in our sample, making it impossible to determine whether experiencing the HRRP penalty led to change in readmission rates at the individual hospital level. ${ }^{10,54}$ Our study should be interpreted in the context of population effects. Coding of dual-eligible patients as Medicare beneficiaries may have skewed our observed Medicare readmissions, especially given that Medicaid coverage increased over time (Table 2), commensurate with ACAfacilitated Medicaid expansion. ${ }^{55}$ Dual-eligible beneficiaries have demonstrably higher healthcare utilization, ${ }^{56}$ and HRRP policy changes in effect as of Fiscal Year 2019 show mitigation of HRRP penalty allocation when stratified by dual-eligible prevalence. ${ }^{57}$ If anything, this limitation would result in underestimation of reductions in the Medicare population, which remained statistically significant despite this limitation. Additionally, we were unable to account for observation stays in this dataset, which may be used to game readmission penalties. The literature surrounding observation stay utilization following penalty implementation in other HRRP conditions is mixed and not studied in COPD. ${ }^{58-61}$

Changes in coding practices used by Medicare occurred in 2011 are suggested to have influenced the risk scores applied to expected readmission calculations and led to exaggerated readmission reduction estimates. ${ }^{62}$ We were not able to riskadjust identically to the HRRP, ${ }^{18,19}$ though our method was in line with current literature using the NRD for this type of analysis. ${ }^{16}$ In our risk-unadjusted sensitivity analysis, the Medicare comparisons fell out of statistical significance compared with non-HRRP and COPD rates fell by significantly less than Phase 1 conditions (Appendix Table 7). The reliability of risk-standardization measures is a matter of ongoing debate. $^{63}$ 


\section{CONCLUSION}

Overall readmission rates for COPD declined concurrently with the introduction and implementation of the HRRP across all payers. Within the targeted Medicare population, these rates fell by greater magnitude than non-HRRP conditions but did not decline significantly more than the comparator of previously penalized HRRP conditions of CHF, AMI, or pneumonia. A potential spillover effect into the private insurance population on readmission reduction was observed for COPD when compared with non-HRRP conditions, while lack of effect within Medicaid further highlights the need for additional risk adjustment for systems with high numbers of low-income patients. Further study as to the effects of adding new conditions to the HRRP should be conducted, inclusive of the unintended morbidity and mortality consequences thereof.

Corresponding Author: Russell G. Buhr, MD, PhD; Division of Pulmonary and Critical Care Medicine, David Geffen School of Medicine, University of California, Los Angeles Los Angeles, CA, USA (e-mail: rbuhr@mednet.ucla.edu).

Author Contributions Drs. Buhr and Jackson had full access to all of the data in the study and take responsibility for the integrity of the data and accuracy of the analysis.

Drs. Buhr, Dubinett, Kominski, Ong, and Mangione contributed to the conception and design of the study.

All authors contributed to the drafting of the manuscript. All of the authors listed above approved this version of the manuscript to be published.

Funding Information This research was supported in part by the University of California at Los Angeles (UCLA) Clinical and Translational Science Institute, National Institutes of Health/National Center for Advancing Translational Science (NCATS) Grant Number UL1TR001881, and the UCLA Joyce and Saul Brandman Fund for Pulmonary Research. The investigators maintained full independence in conducting the research and the funders had no role in the design of the study or interpretation of the results.

Dr. Buhr was supported by NIH/NCATS UCLA CTSI Grant Number TL1TRO01883-01, as well as the UCLA Specialty Training for Advanced Research (STAR) program. Dr. Buhr also received a loan repayment award from NIH National Heart, Lung, and Blood Institute (NHLBI) Grant Number L30HL134025. Dr. Mangione received support from the UCLA Resource Centers for Minority Aging Research Center for Health Improvement of Minority Elderly under National Institutes of Health NIH/NIA under Grant P3OAGO21684 and from the NIH/ NCATS UCLA CTSI under Grant UL1TROO1881. Dr. Mangione holds the Barbara A. Levey and Gerald S. Levey Endowed Chair in Medicine, which partially supported her work.

Contributors and Data Availability Data was made available through the Agency for Healthcare Research and Quality's Healthcare Utilization Project. A full list of partner organizations providing data for the Nationwide Readmissions Database can be found at https:// www.hcup-us.ahrq.gov/db/hcupdatapartners.jsp.

\section{Compliance with Ethical Standards:}

This study was exempted from review based on its use of deidentified, publicly available data by the UCLA Institutional Review Board (IRB No. 18-001208).

Conflict of Interest: Dr. Buhr received personal consulting fees from GlaxoSmithKline and Mylan/Theravance Biopharma, not related to this work.

Dr. Jackson reports nothing to disclose.

Dr. Kominski reports nothing to disclose.
Dr. Dubinett is a member of the scientific advisory boards of Johnson \& Johnson Lung Cancer Initiative, T-cure Bioscience, Cynvenio Biosystems, and EarlyDx, Inc., not related to this work. Dr. Ong reports nothing to disclose.

Dr. Mangione is a member of the United States Preventive Services Task Force (USPSTF). This article does not necessarily represent the views and policies of the USPSTF.

Drs. Buhr, Ong, and Dubinett are employed part-time by the Veterans Health Administration.

Disclaimers: This article does not necessarily represent the views and policies of the Department of Veterans Affairs.

\section{REFERENCES}

1. Jencks SF, Williams MV, Coleman EA. Rehospitalizations among patients in the Medicare fee-for-service program. N Engl J Med. 2009;360(14):1418-28. https://doi.org/10.1056/NEJMsa0803563

2. Patient Protection and Affordable Care Act, Pub. L. No. 111-148, Stat. 124 Stat. 119 (March 23, 2010).

3. Medicare Program; Proposed Changes to the Hospital Inpatient Prospective Payment Systems for Acute Care Hospitals and the Long-Term Care Hospital Prospective Payment System and Fiscal Year 2012 Rates, 76 (2011).

4. Medicare Program; Hospital Inpatient Prospective Payment Systems for Acute Care Hospitals and the Long-Term Care Hospital Prospective Payment System and FY 2012 Rates; Hospitals' FTE Resident Caps for Graduate Medical Education Payment, 76 (2011).

5. Medicare Program; Hospital Inpatient Prospective Payment Systems for Acute Care Hospitals and the Long-Term Care Hospital Prospective Payment System and Proposed Fiscal Year 2014 Rates; Quality Reporting Requirements for Specific Providers; Hospital Conditions of Participation, 78 (2013).

6. Medicare Program; Hospital Inpatient Prospective Payment Systems for Acute Care Hospitals and the Long-Term Care Hospital Prospective Payment System and Fiscal Year 2014 Rates; Quality Reporting Requirements for Specific Providers; Hospital Conditions of Participation; Payment Policies Related to Patient Status, 78 (2013).

7. Healthcare Cost and Utilization Project. Introduction to the HCUP Nationwide Readmissions Database (NRD) 2010-2016. Agency for Healthcare Research and Quality, Rockville, MD. 2018. https://www. hcup-us.ahrq.gov/db/nation/nrd/Introduction_NRD_2010-2016.jsp. Accessed October 152018.

8. Wasfy JH, Zigler CM, Choirat C, Wang Y, Dominici F, Yeh RW. Readmission Rates After Passage of the Hospital Readmissions Reduction Program: A Pre-Post Analysis. Ann Intern Med. 2017;166(5):324-31. https://doi.org/10.7326/m16-0185

9. Ryan AM, Krinsky S, Adler-Milstein J, Damberg CL, Maurer KA, Hollingsworth JM. Association Between Hospitals' Engagement in Value-Based Reforms and Readmission Reduction in the Hospital Readmission Reduction Program. JAMA Intern Med. 2017;177(6):862-8. https://doi.org/10.1001/jamainternmed.2017.0518

10. Desai NR, Ross JS, Kwon JY, Herrin J, Dharmarajan K, Bernheim SM, et al. Association Between Hospital Penalty Status Under the Hospital Readmission Reduction Program and Readmission Rates for Target and Nontarget Conditions. JAMA. 2016;316(24):2647-56. https://doi.org/ 10. 1001/jama.2016.18533

11. Demiralp B, He F, Koenig L. Further Evidence on the System-Wide Effects of the Hospital Readmissions Reduction Program. Health Serv Res. 2018;53(3):1478-97. https://doi.org/10.1111/1475-6773.12701

12. Fingar $\mathbf{K}$, Washington $\mathbf{R}$. Trends in Hospital Readmissions for Four High-Volume Conditions, 2009-2013: Statistical Brief \#196. Rockville (MD): Agency for Healthcare Research and Quality (US); 2015.

13. Myers LC, Faridi MK, Hasegawa K, Hanania NA, Camargo CA, Jr. The Hospital Readmissions Reduction Program and Readmissions for Chronic Obstructive Pulmonary Disease, 2006-2015. Ann Am Thorac Soc. 2019; https://doi.org/10.1513/AnnalsATS.201909-672OC

14. Zuckerman RB, Joynt Maddox KE, Sheingold SH, Chen LM, Epstein AM. Effect of a Hospital-wide Measure on the Readmissions Reduction Program. N Engl J Med. 2017;377(16):1551-8. https://doi.org/10.1056/ NEJMsa1701791

15. Carey K, Lin MY. Readmissions To New York Hospitals Fell For Three Target Conditions From 2008 To 2012, Consistent With Medicare Goals. 
Health Aff (Millwood). 2015;34(6):978-85. https://doi.org/10.1377/ hlthaff.2014.1408

16. Ferro EG, Secemsky EA, Wadhera RK, Choi E, Strom JB, Wasfy JH, et al. Patient Readmission Rates For All Insurance Types After Implementation Of The Hospital Readmissions Reduction Program. Health Aff (Millwood). 2019;38(4):585-93. https://doi.org/10.1377/hlthaff.2018. 05412

17. HCUP. Nationwide Readmissions Database (NRD) [database on the Internet]. Agency for Healthcare Research and Quality. 2010-2016. Available from: https://www.hcup-us.ahrq.gov/nrdoverview.jsp.

18. Yale New Haven Health Services Corporation/Center for Outcomes Research \& Evaluation. 2016 Condition-Specific Measures Updates and Specifications Report Hospital-Level 30-Day Risk-Standardized Readmission Measures. Baltimore, MD: Centers for Medicare \& Medicaid Services; 2016.

19. Yale New Haven Health Services Corporation/Center for Outcomes Research \& Evaluation. 2017 Condition-Specific Measures Updates and Specifications Report Hospital-Level 30-Day Risk-Standardized Readmission Measures. Baltimore, MD: Centers for Medicare \& Medicaid Services; 2017

20. Stagg V. ELIXHAUSER: Stata module to calculate Elixhauser index of comorbidity. Boston College Department of Economics: Statistical Software Components; 2015.

21. Moore BJ, White S, Washington R, Coenen N, Elixhauser A. Identifying Increased Risk of Readmission and In-hospital Mortality Using Hospital Administrative Data: The AHRQ Elixhauser Comorbidity Index. Med Care. 2017;55(7):698-705. https://doi.org/10.1097/MLR. 0000000000000735

22. Buhr RG, Jackson NJ, Kominski GF, Dubinett SM, Ong MK, Mangione CM. Comorbidity and thirty-day hospital readmission odds in chronic obstructive pulmonary disease: a comparison of the Charlson and Elixhauser comorbidity indices. BMC Health Serv Res. 2019;19(1):701. https://doi.org/10.1186/s12913-019-4549-4

23. Joynt KE, Figueroa JE, Oray J, Jha AK. Opinions on the Hospital Readmission Reduction Program: Results of a National Survey of Hospital Leaders. Am J Manag Care. 2016;22(8):e287-94.

24. Regenstein M, Andres E. Reducing hospital readmissions among medicaid patients: a review of the literature. Qual Manag Health Care. 2014;23(1):20-42. https://doi.org/10.1097/qmh.0000000000000016

25. Trudnak T, Kelley D, Zerzan J, Griffith K, Jiang HJ, Fairbrother GL Medicaid Admissions And Readmissions: Understanding The Prevalence. Payment, And Most Common Diagnoses. Health Aff (Millwood) 2014;33(8):1337-44. https://doi.org/10.1377/hlthaff.2013.0632

26. Gai Y, Pachamanova D. Impact of the Medicare hospital readmissions reduction program on vulnerable populations. BMC Health Serv Res. 2019; 19(1):837. https://doi.org/10.1186/s12913-019-4645-5

27. Krishnan JA, Gussin HA, Prieto-Centurion V, Sullivan JL, Zaidi F, Thomashow BM. Integrating COPD into Patient-Centered Hospital Readmissions Reduction Programs. Copd. 2015;2(1):70-80. https://doi. org/10.15326/jcopdf.2.1.2014.0148

28. Press VG, Au DH, Bourbeau J, Dransfield MT, Gershon AS, Krishnan JA, et al. Reducing Chronic Obstructive Pulmonary Disease Hospital Readmissions. An Official American Thoracic Society Workshop Report. Ann Am Thorac Soc. 2019;16(2):161-70. https://doi.org/10.1513/ AnnalsATS.201811-755WS

29. Shah T, Press VG, Huisingh-Scheetz M, White SR. COPD Readmissions: Addressing COPD in the Era of Value-based Health Care. Chest. 2016;150(4):916-26. https://doi.org/10.1016/j.chest.2016.05. 002

30. Fan VS, Gaziano JM, Lew R, Bourbeau J, Adams SG, Leatherman S, et al. A comprehensive care management program to prevent chronic obstructive pulmonary disease hospitalizations: a randomized, controlled trial. Ann Intern Med. 2012;156(10):673-83. https://doi.org/10.7326/ 0003-4819-156-10-201205150-00003

31. Auerbach AD, Kripalani S, Vasilevskis EE, Sehgal N, Lindenauer PK, Metlay JP, et al. Preventability and Causes of Readmissions in a National Cohort of General Medicine Patients. JAMA Intern Med. 2016;176(4):48493. https://doi.org/10.1001/jamainternmed.2015.7863

32. Donzé J, Aujesky D, Williams D, Schnipper JL. Potentially Avoidable 30-Day Hospital Readmissions in Medical Patients: Derivation and Validation of a Prediction Model. JAMA Intern Med. 2013;173(8):632-8. https://doi.org/10.1001/jamainternmed.2013.3023

33. Hakim MA, Garden FL, Jennings MD, Dobler CC. Performance of the LACE index to predict 30-day hospital readmissions in patients with chronic obstructive pulmonary disease. Clin Epidemiol. 2018;10:51-9. https://doi.org/10.2147/clep.S149574
34. Wang H, Robinson RD, Johnson C, Zenarosa NR, Jayswal RD Keithley $\mathbf{J}$, et al. Using the LACE index to predict hospital readmissions in congestive heart failure patients. BMC Cardiovasc Disord. 2014;14:97. https://doi.org/10.1186/1471-2261-14-97

35. Buhr RG, Jackson NJ, Kominski GF, Dubinett SM, Mangione CM, Ong MK. Factors associated with differential readmission diagnoses following acute exacerbations of chronic obstructive pulmonary disease. J Hosp Med. 2020;15. https://doi.org/10.12788/jhm.3367

36. Press VG, Miller BJ. The Hospital Readmissions Reduction Program and COPD: More Answers, More Questions. J Hosp Med. 2020; https://doi. org/10.12788/jhm.3362

37. Wadhera RK, Joynt Maddox KE, Wasfy JH, Haneuse S, Shen C, Yeh RW. Association of the Hospital Readmissions Reduction Program With Mortality Among Medicare Beneficiaries Hospitalized for Heart Failure, Acute Myocardial Infarction, and Pneumonia. JAMA. 2018;320(24):2542 52. https://doi.org/10.1001/jama.2018.19232

38. Dharmarajan $\mathbf{K}$, Wang $\mathbf{Y}$, Lin $\mathbf{Z}$, et al. Association of changing hospital readmission rates with mortality rates after hospital discharge. JAMA. 2017;318(3):270-8. https://doi.org/10.1001/jama.2017.8444

39. Samarghandi A, Gayyum R. Effect of Hospital Readmission Reduction Program on Hospital Readmissions and Mortality Rates. J Hosp Med. 2019;14:E25-e30. https://doi.org/10.12788/jhm.3302

40. Carey K, Lin MY. Hospital Readmissions Reduction Program: Safety-Net Hospitals Show Improvement, Modifications To Penalty Formula Still Needed. Health Aff (Millwood). 2016;35(10):1918-23. https://doi.org/10. 1377 /hlthaff.2016.0537

41. Gu Q, Koenig L, Faerberg J, Steinberg CR, Vaz C, Wheatley MP. The Medicare Hospital Readmissions Reduction Program: potential unintended consequences for hospitals serving vulnerable populations. Health Serv Res. 2014;49(3):818-37. https://doi.org/10.1111/1475-6773. 12150

42. Salerno AM, Horwitz LI, Kwon JY, Herrin J, Grady JN, Lin Z, et al. Trends in readmission rates for safety net hospitals and non-safety net hospitals in the era of the US Hospital Readmission Reduction Program: a retrospective time series analysis using Medicare administrative claims data from 2008 to 2015. BMJ Open. 2017;7(7):e016149. https://doi.org/ 10.1136/bmjopen-2017-016149

43. Sheingold SH, Zuckerman R, Shartzer A. Understanding Medicare Hospital Readmission Rates And Differing Penalties Between Safety-Net And Other Hospitals. Health Aff (Millwood). 2016;35(1):124-31. https:// doi.org/10.1377/hlthaff.2015.0534

44. Sjoding MW, Cooke CR. Readmission Penalties for Chronic Obstructive Pulmonary Disease Will Further Stress Hospitals Caring for Vulnerable Patient Populations. Am J Respir Crit Care Med. 2014;190(9):1072-4. https://doi.org/10.1164/rccm.201407-1345LE

45. Feemster LC, Au DH. Penalizing hospitals for chronic obstructive pulmonary disease readmissions. Am J Respir Crit Care Med. 2014;189(6):634-9. https://doi.org/10.1164/rccm.201308-1541PP

46. Rinne ST, Castaneda J, Lindenauer PK, Cleary PD, Paz HL, Gomez JL. Chronic Obstructive Pulmonary Disease Readmissions and Other Mea sures of Hospital Quality. Am J Resp Crit Care Med. 2017;196(1):47-55. https://doi.org/10.1164/rccm.201609-1944OC

47. McCarthy B, Casey D, Devane D, Murphy K, Murphy E, Lacasse Y Pulmonary rehabilitation for chronic obstructive pulmonary disease. Cochrane Database Syst Rev. 2015;(2):Cd003793. https://doi.org/10. 1002/14651858.CD003793.pub3

48. Puhan MA, Gimeno-Santos E, Cates CJ, Troosters T. Pulmonary rehabilitation following exacerbations of chronic obstructive pulmonary disease. Cochrane Database Syst Rev. 2016;12:Cd005305. https://doi. org/10.1002/14651858.CD005305.pub4

49. Williams MT, Effing TW, Paquet C, Gibbs CA, Lewthwaite H, Li LSK, et al. Counseling for health behavior change in people with COPD: systematic review. Int $\mathrm{J}$ Chron Obstruct Pulmon Dis. 2017;12:2165-78. https://doi.org/10.2147/copd.S111135

50. van Eerd EA, van der Meer RM, van Schayck OC, Kotz D. Smoking cessation for people with chronic obstructive pulmonary disease. Cochrane Database Syst Rev. 2016;(8):Cd010744. https://doi.org/10. 1002/14651858.CD010744.pub2

51. Bekkat-Berkani R, Wilkinson T, Buchy P, Dos Santos G, Stefanidis D, Devaster JM, et al. Seasonal influenza vaccination in patients with COPD: a systematic literature review. BMC Pulm Med. 2017;17(1):79. https://doi.org/10.1186/s12890-017-0420-8

52. Walters JA, Tang JN, Poole P, Wood-Baker $\mathbf{R}$. Pneumococcal vaccines for preventing pneumonia in chronic obstructive pulmonary disease Cochrane Database Syst Rev. 2017;1:Cd001390. https://doi.org/10. 1002/14651858.CD001390.pub4 
53. Global Initiative for Chronic Obstructive Lung Disease. Global Strategy for the Prevention, Diagnosis, and Management of COPD. Fontana, WI 2019. https://goldcopd.org/wp-content/uploads/2018/11/GOLD2019-v1.7-FINAL-14Nov2018-WMS.pdf.

54. Joshi S, Nuckols T, Escarce J, Huckfeldt P, Popescu I, Sood N. Regression to the Mean in the Medicare Hospital Readmissions Reduction Program. JAMA Intern Med. 2019;179(9):1167-73. https://doi.org/10. 1001/jamainternmed.2019.1004

55. Kaiser Family Foundation. Status of State Action on the Medicaid Expansion Decision. 2019. https://www.kff.org/health-reform/state-indicator/state-activity-around-expanding-medicaid-under-the-affordablecare-act. Accessed November 62019.

56. Bennett KJ, Probst JC. Thirty-Day Readmission Rates Among DualEligible Beneficiaries. J Rural Health. 2016;32(2):188-95. https://doi. org/10.1111/jrh. 12140

57. Joynt Maddox KE, Reidhead M, Gi AC, Nerenz DR. Association of Stratification by Dual Enrollment Status With Financial Penalties in the Hospital Readmissions Reduction Program. JAMA Intern Med. 2019;179(6):769-76. https://doi.org/10.1001/jamainternmed.2019. 0117

58. Zuckerman RB, Sheingold SH, Orav EJ, Ruhter J, Epstein AM. Readmissions, Observation, and the Hospital Readmissions Reduction Program. N Engl J Med. 2016;374(16):1543-51. https://doi.org/10. 1056/NEJMsa1513024

59. Wadhera RK, Joynt Maddox KE, Kazi DS, Shen C, Yeh RW. Hospital revisits within 30 days after discharge for medical conditions targeted by the Hospital Readmissions Reduction Program in the United States: national retrospective analysis. BMJ. 2019;366:14563. https://doi.org/ 10.1136/bmj.14563

60. Chhabra KR, Ibrahim AM, Thumma JR, Ryan AM, Dimick JB. Impact Of Medicare Readmissions Penalties On Targeted Surgical Conditions. Health Aff (Millwood). 2019;38(7):1207-15. https://doi.org/10.1377/ hlthaff.2019.00096

61. Albritton J, Belnap Tw, Savitz LA. The Effect Of The Hospital Readmissions Reduction Program On Readmission And Observation Stay Rates For Heart Failure. Health Aff (Millwood). 2018;37(10):16329. https://doi.org/10.1377/hlthaff.2018.0064

62. Ody C, Msall L, Dafny LS, Grabowski DC, Cutler DM. Decreases In Readmissions Credited To Medicare's Program To Reduce Hospital Readmissions Have Been Overstated. Health Aff (Millwood). 2019;38(1):36-43. https://doi.org/10.1377/hlthaff.2018.05178

63. Thompson MP, Kaplan CM, Cao Y, Bazzoli GJ, Waters TM. Reliability of 30-Day Readmission Measures Used in the Hospital Readmission Reduction Program. Health Serv Res. 2016;51(6):2095-114. https://doi. org/10.1111/1475-6773.12587

Publisher's Note: Springer Nature remains neutral with regard to jurisdictional claims in published maps and institutional affiliations. 